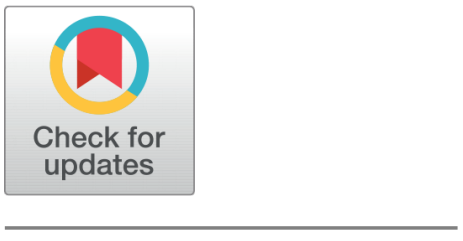

OPEN ACCESS

Received: 04.01.2021

Accepted: 22.03.2021

Published: 14.04 .2021

Citation: Khan MT, Nafees KA, Singh AK (2021) Interaction of Pc4 ULF waves with solar wind velocity and its dependence on Kp values. Indian Journal of Science and Technology 14(12): 1013-1020. https ://doi.org/10.17485/IJST/v14i12.2317

* Corresponding author.

mtpathan@gmail.com

Funding: None

Competing Interests: None

Copyright: $₫ 2021$ Khan et al. This is an open access article distributed under the terms of the Creative Commons Attribution License, which permits unrestricted use, distribution, and reproduction in any medium, provided the original author and source are credited.

Published By Indian Society for Education and Environment (iSee)

ISSN

Print: 0974-6846

Electronic: 0974-5645

\section{Interaction of Pc4 ULF waves with solar wind velocity and its dependence on $\mathrm{Kp}$ values}

\author{
M T Khan ${ }^{1 *}$, K A Nafees ${ }^{2}$, A K Singh ${ }^{3}$ \\ 1 Department of Physics, G.F. College, Shahjahanpur, 242001, UP, India \\ 2 Dept. of App. Physics, Adama Sci. \& Tech. University, Adama, Ethiopia \\ 3 Department of Physics, Bareilly College, Bareilly, 234001, UP, India
}

\section{Abstract}

Background/Objectives: Magnetic Pulsations recorded on the ground in the earth are produced by processes inside the magnetosphere and solar wind. These processes produce a wide variety of ULF hydromagnetic wave type which can be categorized on the ground as either Pi or Pc pulsations (irregular or continuous). Methods: Distinctive regions of the magnetosphere originate different frequencies of waves. Digital Dynamic Spectra (DDS) for the northsouth $(X)$, east-west $(Y)$ and vertical $(Z)$ components of the recorded data were constructed for every day for 365 days (January 1 to December 31, 2005) in the station order PON, HAN and NAG respectively. Pc4 geomagnetic pulsations are quasi-sinusoidal fluctuations in the earth's magnetic field in the length range 45-150 seconds. The magnitude of these pulsations ranges from fraction of a Nano Tesla (nT) to several nT. The monthly variation of Pc4 occurrence has a $\mathrm{Kp}$ dependence range of 0 to 9-. However, Pc4 occurrence was reported for Kp values, yet the major Pc4 events occurred for rage $5+<K p<8+$. The magnitudes of intervals of Pc4 occurrence decreased in the station order PON, HAN and NAG respectively. Analysis of the data for the whole year 2005 provided similar patterns of Pc4 occurrence for Vsw at all the three stations. Although Pc4 ULF wave occurrence become reported for Vsw ranging from 250 to $1000 \mathrm{Km} / \mathrm{s}$, yet the major Pc4 event recorded for a Vsw range of 300-700 Km/sec. Findings: The current study is undertaken for describing the interaction of Pc4 ULF waves with solar wind speed and its dependence on Kp values. The results suggest that the solar wind control Pc4 occurrence through a mechanism in which Pc4 wave energy is convected through the magnetosheath and coupled to the standing oscillations of the magnetospheric field lines.

PACS Nos: 94.30.cq; 96.50.Tf

Keywords: Geomagnetic micropulsations; MHD waves and instabilities; Solar wind-control of Pc4 pulsation 


\section{Ultra low frequency (ULF}

Ultra low frequency (ULF) waves incident within the Earth's atmosphere are produced by means of approaches within the magnetosphere and solar wind. These approaches produce a wide variety type of ULF hydromagnetic waves. Distinctive frequencies of waves and polarizations originate in different regions of the magnetosphere. Extremely low frequency waves (magnetic pulsations) are because of hydromagnetic waves that can be generated due to different types of plasma instabilities inside the magnetosphere or on its boundary in a completely complicated manner. In this paper, the origination of hydromagnetic waves, their sources internal and external to the magnetosphere and their propagation and modification in the magnetosphere and ionosphere are in brief mentioned. A very good summary of those topics, with references to the most significant publication dealing with ULF waves, has elegantly been reported by McPherron ${ }^{(1)}$, Southwood and Hughes ${ }^{(2)}$ and additionally presented within the books "Introduction to Space Physics", ${ }^{(3)}$ and "Geomagnetic Micropulsations" (4). The facts given in this paper is especially mentioned from those publications and references contained therein. They have a look at might be very effective in research of magnetic field variation of earth. This will ultimately provide a perception to future of upper atmosphere.

The intensity of magnetic disturbances will increase from low to high latitudes up to range of the auroral zones, i.e. approximately magnetic latitude $65^{\circ}$. In the high latitudes, magnetograms are seldom completely undisturbed. Intense magnetic storms generally commence abruptly at same moment all around the Earth. Further to large-scale magnetic storms there are disturbances of an awful lot shorter duration, along with polar magnetic sub-storms and bays. Abrupt impulsive change (surprising impulses) may also arise and are regularly determined simultaneously everywhere in the world and feature additionally been detected within the magnetosphere. Variation with periods more or less from $0.1 \mathrm{~s}$ to $10 \mathrm{~min}$ are grouped collectively and termed as geomagnetic micropulsations ${ }^{(2-5)}$.

The diurnal variation of occurrence and frequency of Pc3-4 waves recorded at ground station and their dependence on range and geomagnetic indices $\mathrm{Kp}$ and also identify their source and propagation modes. The present study describes the interaction of Pc4 ULF waves with solar wind and its dependence on Kp values.

\section{Data Analysis and Results}

The data of all of the stations has been sampled at 1s time interval. Digital dynamic spectra (DDS) for the north-south (X) eastwest $(\mathrm{Y})$ and vertical $(\mathrm{Z})$ components of the recorded data had been constructed for every day for one year period. The $\mathrm{X}$ - and Y-components of these DDS have been investigated for undertaking the above diurnal and seasonal statistical study ${ }^{(5-8)}$. The stations were situated at very low latitudes in India. The magnetometer array was established and operated by Indian Institute of Geomagnetism, Navi Mumbai. The coordinate details of these stations and the schematic representation of their locations are shown in Table 1. The DDS of the time series for 24 hours have been constructed for the complete year 2005 for all of the given stations. These DDS enabled us to recognize the pulsation events depicted in Figure 1. We observed the micropulsation events at all of the stations on several dates. Almost the pulsation events had been found in the 10 to $30 \mathrm{mHz}$ frequencies ranges The facts of Vsw for the year 2005 are received from of National Aeronautics and Space Administration (NASA).

Table 1. Coordinate details of recording stations

\begin{tabular}{|c|c|c|c|c|}
\hline Recording stations & \multicolumn{2}{|c|}{$\begin{array}{l}\text { Geographic co-ordinates } \\
\text { Long. }{ }^{\circ} \text { E Lat. }{ }^{\circ} \mathrm{N}\end{array}$} & \multicolumn{2}{|c|}{$\begin{array}{l}\text { Geomagnetic co-ordinates } \\
\text { Long. }{ }^{\circ} \text { E Lat. }{ }^{\circ} \mathrm{N}\end{array}$} \\
\hline Pondicherry(PON & 79.92 & 11.92 & 151.97 & 02.50 \\
\hline Nagpur (NAG) & 79.00 & 21.10 & 151.93 & 11.72 \\
\hline Hanle (HAN) & 78.97 & 32.78 & 151.89 & 23.38 \\
\hline
\end{tabular}



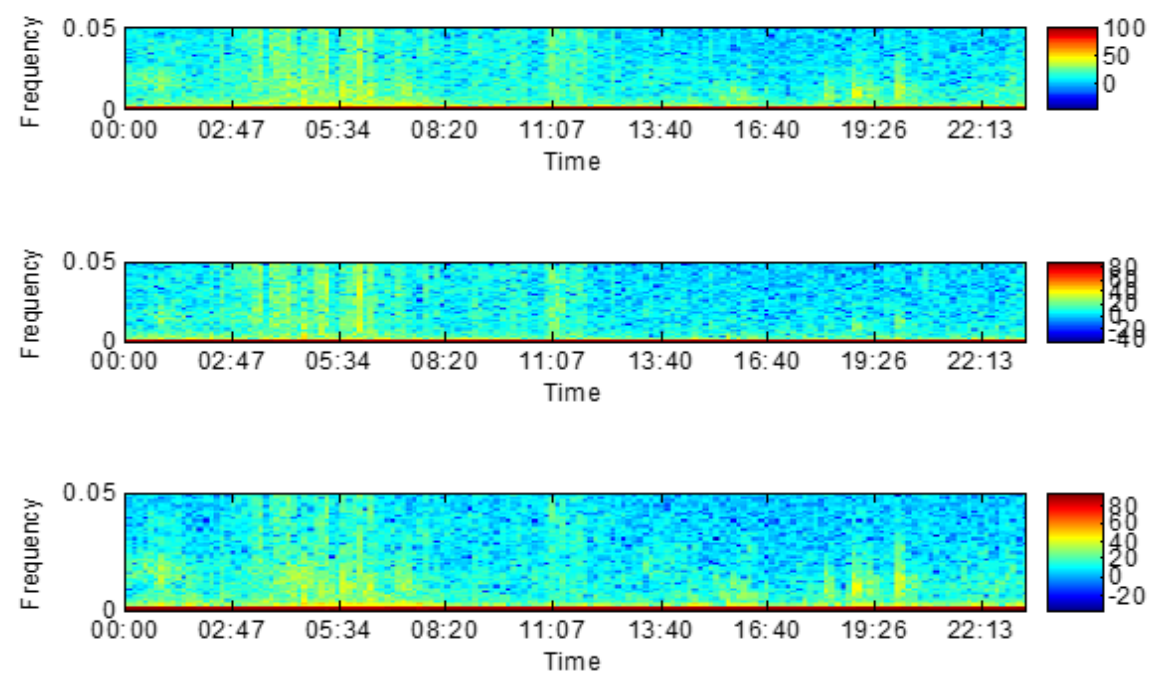

Fig 1. Full day dynamic spectra on $1^{\text {st }}$ April 2005 for Pondicherry. Frequency is given in Hz while time (UT) is depicted in seconds. The colours shown on right are indicating relative intensities

The recorded time series of magnetic intensity with 1 s period in-between period were filtered using a 0 -phase shift sixth order Butterworth type "band pass" filter with limits of the frequency range $5-40 \mathrm{mHz}^{(9)}$. Figure 2 suggests the filtered time series of pulsations for Hanle recording station on January 28, 2005.

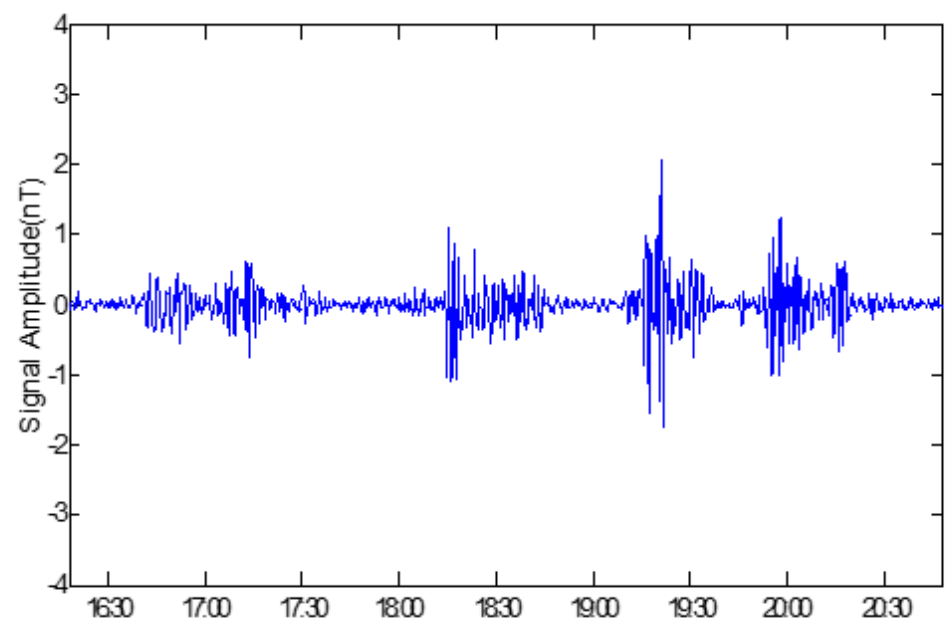

Fig 2. Filtered time series of selected data of 28th Janaury-2005(Hanle) in UT

The variation of Pc4 occurrence on Kp values for January, 2005 is depicted in Figure 3. Similar variation of Pc4 occurrence with $\mathrm{Kp}$ are observed at all the three stations. However prominent peaks in Pc4 occurrence are situated at Kp = 3-, 4 and 6+. The plots for the individual months of February to December, 2005 are not depicted. However, these show variable pattern for each month with prominent Pc4 maxima occurring at $\mathrm{Kp}=0+, 2-, 3+, 4-$ and 4+ (for February,2005); Kp = 2-, 3-, 3, 3+ and 4(for March, 2005); $\mathrm{Kp}=0+, 1-, 1+, 3-, 3+$ and 4+ (for April, 2005); $\mathrm{Kp}=2$, 3, 5, 6- and 8+ (for May, 2005); Kp = 1-, 1+, 2-, 2, 4-, 4+, 6- and 7 (for June, 2005); Kp = 1-, 1+, 22-, 2+, 3+, 4- and 4+ (for July, 2005); Kp = 3, 3- (for August, 2005); Kp = 1, 6-, 7 and 8- 9for September, 2005); Kp = 0+, 1-, 1+, 2 and 3+ (for October, 2005); Kp = 1-, 1, 1+, 2-, 3, 3+ and 4+ (for November, 2005); and $\mathrm{Kp}=2-, 2,3-, 3,3+$ and $4-\left(\right.$ for December, 2005) ${ }^{(6)}$. 


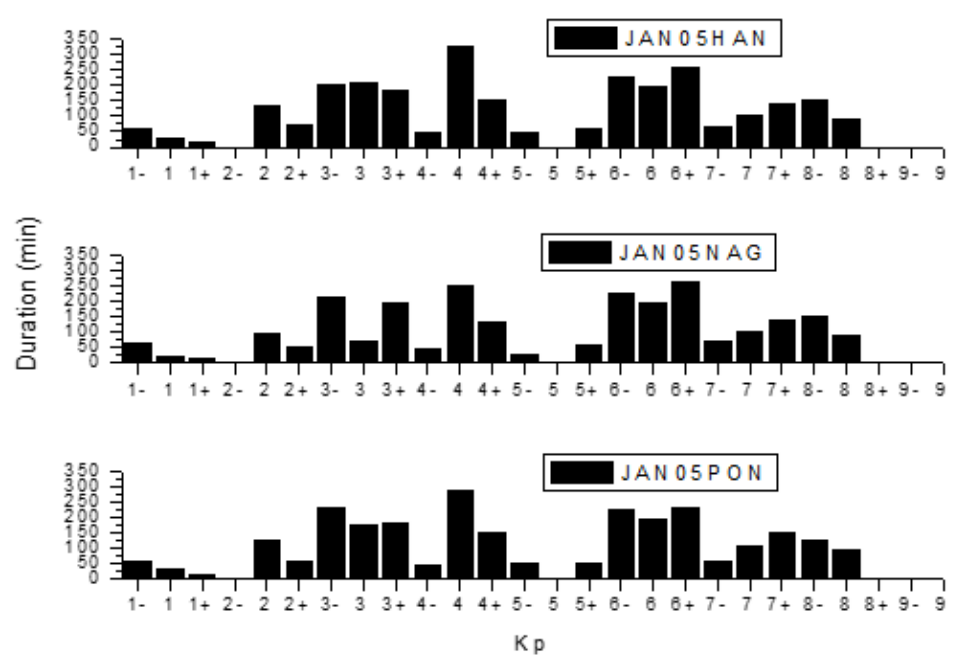

Fig 3. Variation of Pc4 Occurrence (in minutes) with Kp for the month January, 2005

All of these consequences are not depicted for carrying out brief reporting. Only one of the representative outcomes for the Spring season, 2005 represented in Figure 4. Figure 4 shows the Kp dependence of the occurrence of Pc4 waves for the Spring season of 2005. Prominent peaks in Pc4 occurrence are shown at $\mathrm{Kp}=1-, 1,2+, 3-, 3,3+$, 4- with an additional peak at $\mathrm{Kp}=8+$ at all the three stations. However, those show variable pattern for every season with distinguished Pc4 maxima occurring at Kp $=1,2,2+, 3-, 3,4-$, fo, 4 and $4+$ at all of the 3 stations and further peaks are located at $\mathrm{Kp}=6+$ and 8 at Nagpur and Pondicherry (For summer season, 2005); $\mathrm{Kp}=1-, 1,1+, 2-, 2,3$ and 4+ at all of the 3 stations and additional peaks are discovered at $\mathrm{Kp}=$ 6, 7- and 8 at Nagpur and Pondicherry (For Autumn season of 2005); Kp = 0+, 1, 2, 2+, 3-, 3, 3+, four, 6, 6, 7- and 8- at all the three station (For winter season of 2005).
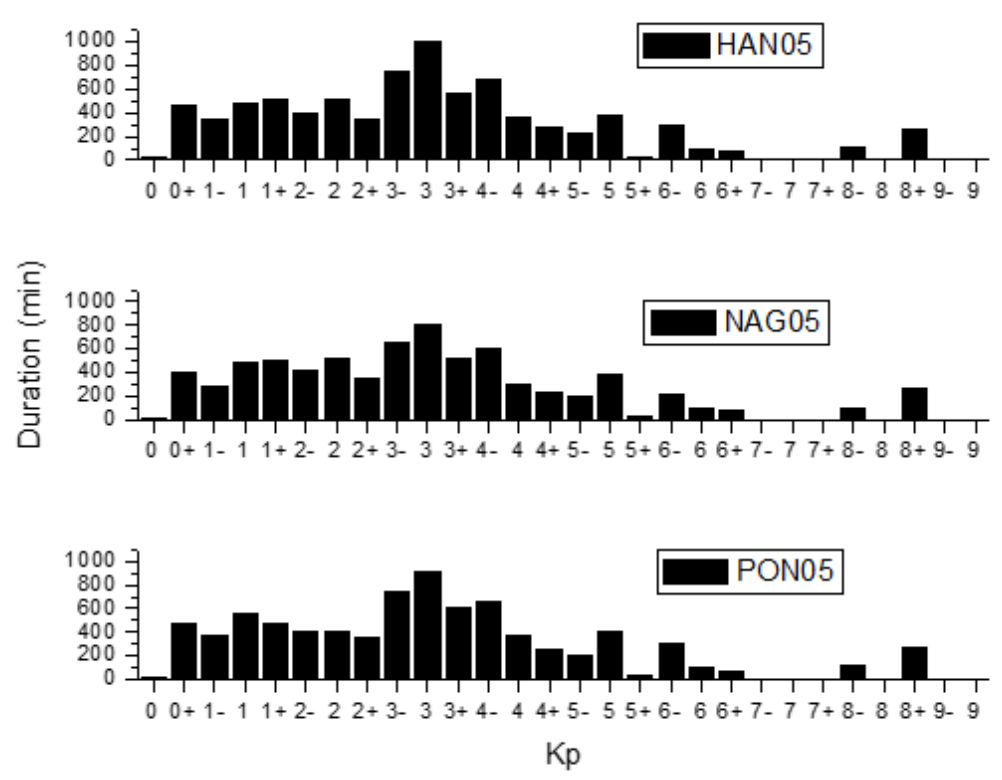

Fig 4. Variation of Pc4 Occurrence (in minutes) with Kp for the Spring season of 2005 
The Kp dependence of Pc4 occurrence for the whole year 2005 is shown in Figure 5. Although major prominent peaks are situated at $\mathrm{Kp}=3,3$ - and 3+, there are minor prominent peaks present at $\mathrm{Kp}=0+, 1-, 1,1+, 2,4,4+, 6-, 6+, 7$ and 8 -
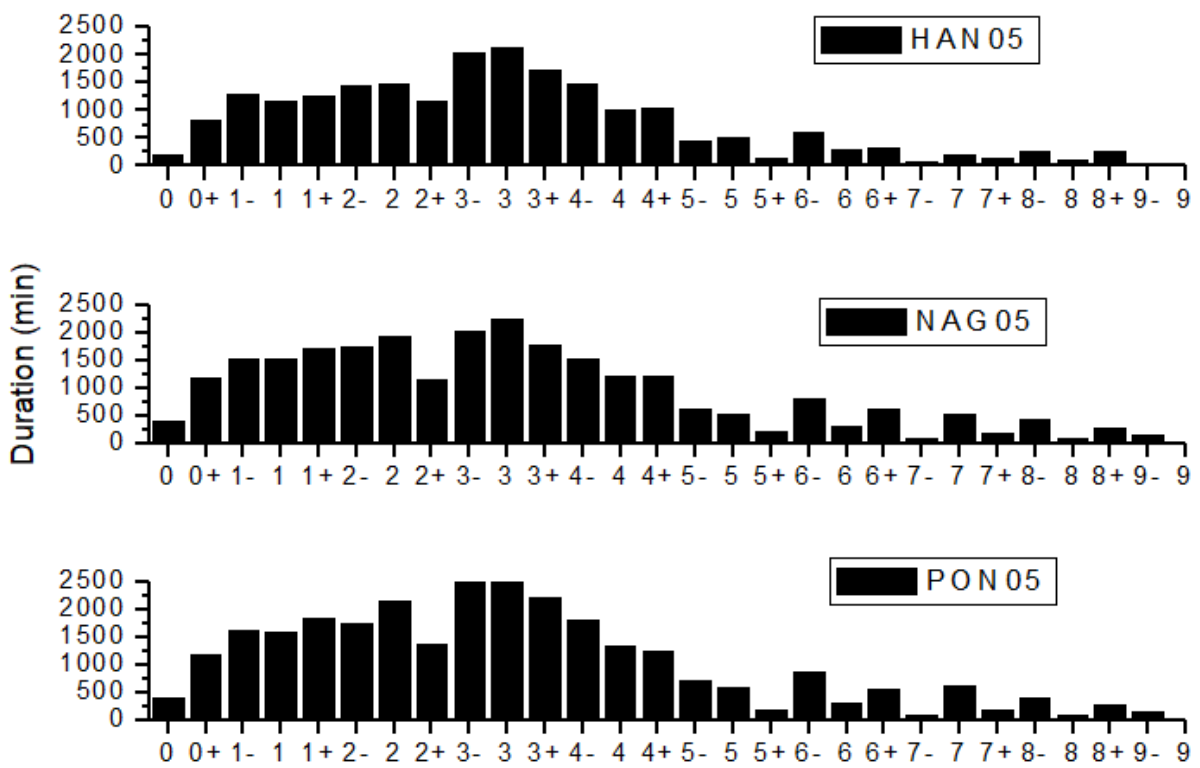

$\mathrm{Kp}$

Fig 5. Variation of Pc4 Occurrence (in minutes) with Kp for the whole year 2005

The investigation of the dependence of Pc4 event on Vsw turned into also undertaken for all the several months of the year. All these results aren't presented for carrying out brief reporting. Only one of the typical outcomes for the individual month of March, 2005 is presented in Figure 6. The solar wind expressed in $\mathrm{km} / \mathrm{s}$ at the X-axis and total duration of events for the corresponding value of solar wind velocity for the whole month is given in minutes on the Y-axis. It's clear from the graph that at all the stations, nearly same pattern of dependence of Pc4 occurrence on Vsw is observed. The value of Vsw ranged from 300 $\mathrm{km} / \mathrm{s}$ to $700 \mathrm{~km} / \mathrm{s}$. But Pc4 events were found for all most all values of Vsw on this variation.
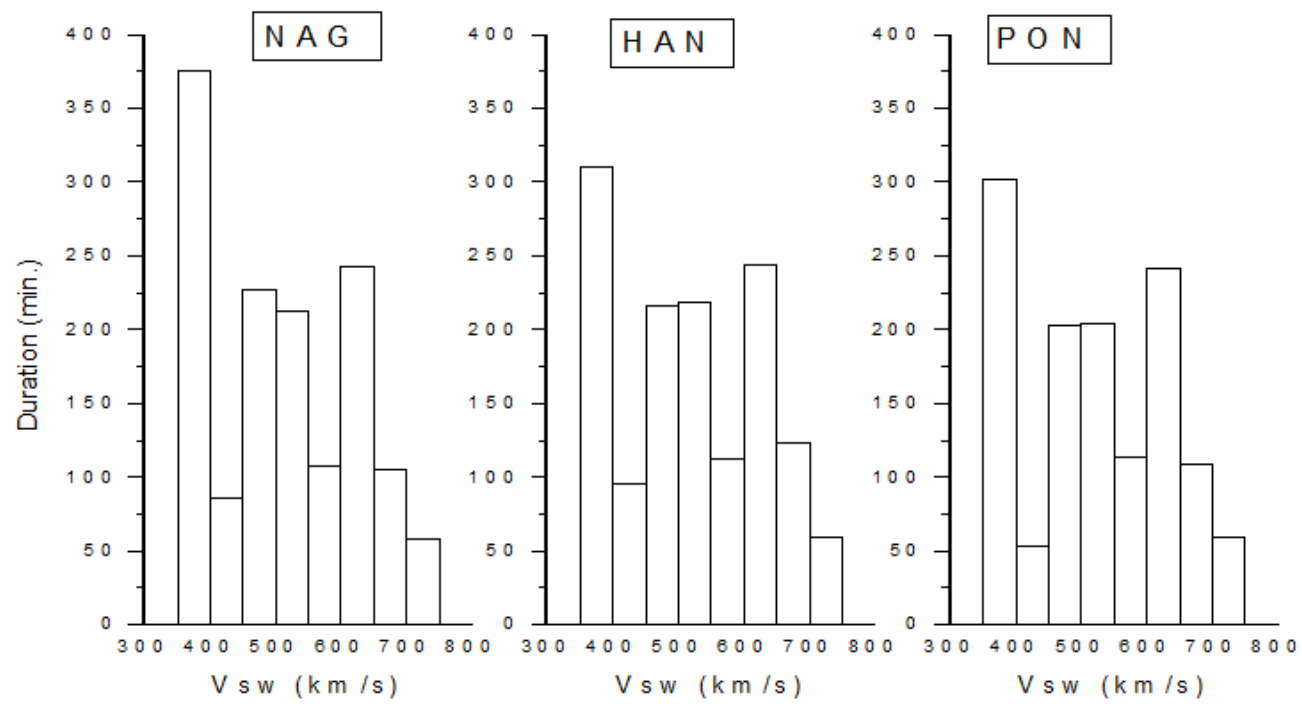

Fig 6. Dependence of activities duration on solar wind for all three stations Nagpur, Hanle and Pondicherry in month of March 2005 
The maximum value of duration of activities at Nagpur was observed to be 489 min similar to Vsw values of 400 - 450 $\mathrm{km} / \mathrm{s}$. At Hanle, the main peak of period turned into of 472 minute. Similar pattern were also found at Pondicherry with the maximum occurrence peek having duration of $490 \mathrm{~min}$ analogous to Vsw values of $400-450 \mathrm{~km} / \mathrm{s}$. The statistical consequences on the dependence of Pc4 occurrence on Kp and Vsw for the complete year 2005 provided entirely details. The dependence of Pc4 pulsations occurance on Vsw for the whole year 2005 observed at all the three stations is depicted in Figure 7. Its miles obtrusive from the figure that comparable patterns of Pc4 occurrence with Vsw had been determined all of the three stations. Pc4 occurrence reported for Vsw starting from 250 to $1000 \mathrm{~km} / \mathrm{s}$. But major Pc4 events took place for a Vsw range of $300-700$ $\mathrm{km} / \mathrm{s}^{(10-12)}$.

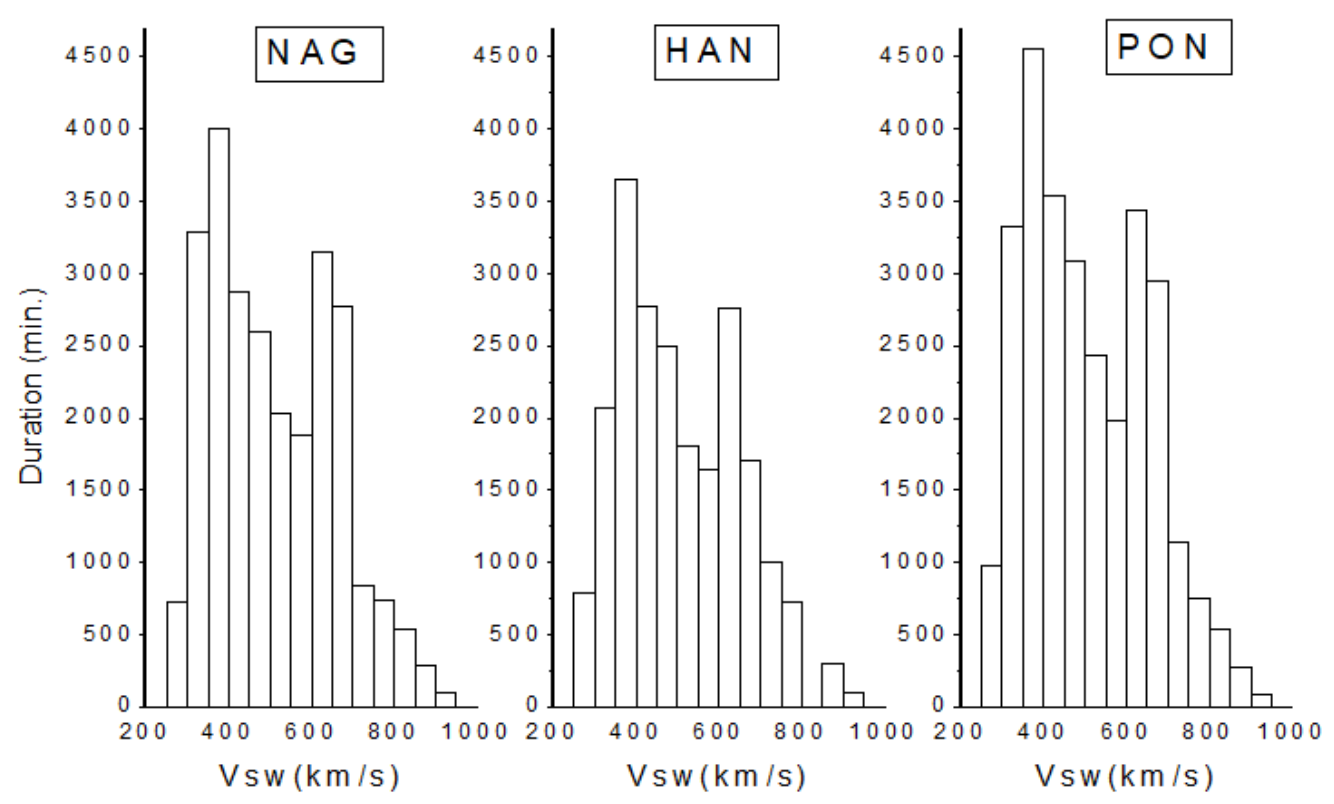

Fig 7. Dependence of activities duration on solar wind for all three stations Nagpur, Hanle and Pondicherry in whole yr 2005

\section{Discussion and conclusion}

Pc4 Magnetic Pulsation perceived on earth may either both be internal or external to the magnetosphere. This mechanism was observed to be most achievable for shorter wavelengths and prominent localization in longitude. Such localized waves were found in space at geostationary orbit ${ }^{(7,8)}$ however are screened from the ground via the magnetosphere. Till date is no comprehensive theory of inner excitation of Pc4 waves that would explain the external restraint that is compatible with observations and usually models for the external excitation of these waves are preferred ${ }^{(9)}$. There are two places for the external origin of pulsations, at the magnetopause, and upstream from the magnetopause. Surface waves generated by using KelvinHelmholtz instability are vital on the magnetopause ${ }^{(13-15)}$. Upstream from the magnetopause, large amplitude waves in the quasi-parallel bow shock are swept returned into the magnetosheath and then penetrate the magnetosphere ${ }^{(16)}$.

The Ist direct proof for the propagation of external Pc3-4 wave power into the magnetosphere has been introduced by Greenstadt et al. ${ }^{(17)}$. Utilizing a couple of individual event from the ISEE 1-2 spacecraft they have confirmed that similar frequencies in the $10-100 \mathrm{mHz}$ band were found in the magnetosheath and also in the magnetosphere however lower power was found there. Same results were reported by Tomomura et al. from a half year of ISEE data in the $3-30 \mathrm{mHz}^{\mathrm{band}}{ }^{(18)}$. These authors further exhibited that the compressional oscillations dominated in the magnetosheath around nearby early afternoon while transverse Alfven waves were found inside the magnetosphere. The transmission of upstream wave energy into the magnetosphere likely originates predominantly near the subsolar region. This is a necessity for these waves to access low latitudes. The index of refraction of the magnetospheric plasma diminishes with diminishing radial distance besides at the plasmapause ${ }^{(19)}$. This diminishing ought to refract waves away from radial propagation lessening the wave energy that can penetrate to low latitudes, permitting access just to those waves that are almost radially propagating. This is upheld by the consequences of Tomomura et al. ${ }^{(20)}$ who have shown that the wave spectral power is created in the magnetosheath around 
early afternoon. In the event that it is expected that significant Pc3-4 wave energy can penetrate to low latitudes, at that point there are various conceivable excitation mechanism accessible for wave generation. These are cumulative transverse surface wave eigen fluctuations at the plasmapause (Lpp); essential toroidal mode standing oscillation at $\mathrm{L}=1.1$ and $\mathrm{L}=1.76-2.6$ and higher order hormonics at L = 2.0 - Lpp; and trapped oscillations in the equatorial plane between the two peaks of the Alfven speed at $\mathrm{L}=1.7-\mathrm{Lpp}^{(13)}$.

In the light of the above examined excitation mechanism and the obtained results of the diurnal and seasonal variations of low latitude Pc4 pulsations, it is recommended that the upstream waves are a significant source of Pc4 pulsations recorded on the nightside which were started on the dayside and most likely by an extended region of ULF waves. It is also proposed that the plasmaspheric cavity mode reverberation may have assumed a role in sifting the broadband input to the magnetosphere. The results of the current examination are additionally in concurrence with the observed characteristic of ULF upstream waves ${ }^{(21)}$.

The month to month variation of Pc4 event has a Kp dependence range of 0 to 9-. However, the yearly Pc4 event was observed to be equitably distributed with magnetic activity over the $\mathrm{Kp}=2$ - to 4 range at all the three stations with the peak event recorded at $\mathrm{Kp}=3$-. The magnitude of duration of Pc4 event diminished in the station order PON, HAN and NAG respectively. The prominent peaks in the seasonal Pc4 event were found at $\mathrm{Kp}=3-, 3$ for all the seasons. However additional pinnacles were seen at $\mathrm{Kp}=1-, 1$ and $1+$ for the autumn season. It is additionally important that Pc4 in winter was found during extreme magnetic activity when $5+<\mathrm{Kp}<8+{ }^{(22)}$.

In the current examination, the outcomes are in agreement with recommendations of Takahashi ${ }^{(23)}$ who reported that the pulsations detected on the nightside started on the dayside and most likely by an extended region of ULF waves in front of the bow shock and not from processes occurring in the nightside magnetosphere as there was absence of substorm onsets or intensification. Similar outcomes were also reported by Villante et al. ${ }^{(24)}$. The main peaks in Pc4 occurrence at local winter and local autumn found at the same time at all the three stations agree with the previous studies of Ansari and Fraser ${ }^{(20)}$ and Kuwashima et al. ${ }^{(24)}$ where the main occurrence peaks in winter and equinox did not change with time. As the stations array was spread over a latitudinal range of $21^{\circ}$ only, it was not sufficient for identification of latitude dependence of Pc4 pulsation occurrence since the data from large-scale latitudinal separation was required for this purpose.

In conclusion, it has been demonstrated that the occurrence of Pc4 pulsations depends on solar wind velocity with a threshold at about $250 \mathrm{~km} / \mathrm{s}$ and ranging up to $950 \mathrm{~km} / \mathrm{s}$. It is likely that an instability originating from the direct interaction between the solar wind and the magnetosphere is exciting Pc4 pulsations through bow-shock associated waves.

\section{Acknowledgements}

The authors are thankful to the Director, Indian Institute of Geomagnetism (IIG) Navi Mumbai, India for kindly providing Pc4 pulsations data.

\section{References}

1) Pherron RLM. Magnetospheric dynamics. In: Kivelson MG, Russell CT, editors. Introduction to space physics. New York, Melbourne. Cambridge Uni. Press. 1995;p. 1-569. Available from: https://books.google.co.in/books/about/Introduction_to_Space_Physics.html?id=DIybBQAAQBAJ\&redir_esc=y.

2) Kivelson MG, Russell CT. Introduction to space physics. New York, Melbourne. Cambridge University Press. 2019. Available from: https://doi.org/10. $1017 / 9781139878296$.

3) Southwood DJ, Hughes WJ. Theory of hydromagnetic waves in the magnetosphere. Space Science Reviews. 1983;35(4):301-366. Available from: https://dx.doi.org/10.1007/bf00169231.

4) Jacobs JA. Geomagnetic Micropulsations. Berlin, Germany. Springer-Verlag. 1970. Available from: https://www.springer.com/gp/book/9783642868306.

5) Pathan BM, Kleimenova NG, Kozyreva OV, Rao DRK, Asinkar RL. Equatorial enhancement of Pc5-6 magnetic storm time geomagnetic pulsations. Earth, Planets and Space. 1999;51(9):959-964. Available from: https://dx.doi.org/10.1186/bf03351566.

6) Khan MT, and MA. Statistical Characteristic of Pc4 Magnetic Micropulsations at low latitude in India. Remarking an Analisation. 2018;3(4):16-26. Available from: http://www.socialresearchfoundation.com/upoadreserchpapers/5/220/1809130620061.

7) Cummings WD, O’Sullivan RJ, Coleman PJ. Standing Alfvén waves in the magnetosphere. Journal of Geophysical Research. 1969;74(3):778-793. Available from: https://dx.doi.org/10.1029/ja074i003p00778.

8) Cummings WD, DeForest SE, McPherron RL. Measurements of the Poynting vector of standing hydromagnetic waves at geosynchronous orbit. Journal of Geophysical Research. 1978;83(A2). Available from: https://dx.doi.org/10.1029/ja083ia02p00697.

9) Ansari IA. Multipoint observations of low latitude ULF Pc3 waves in south-east Australia. Journal of Astrophysics and Astronomy. 2008;29(1-2):303-311. Available from: https://dx.doi.org/10.1007/s12036-008-0040-z.

10) Kuwashima M, Sano Y, Kawamura M. On the Geomagnetic Pulsations Pc3 (Part III)-Spectraland Polarization Characteristics of Middle- and LowLatitude Pc3, Memoirs of Kakioka Magnetic Observatory. 1979. Available from: https://doi.org/10.5636/jgg.40.33.

11) Nafees KA, Khan MT, Anno AK, Shaikh JR. Correlation of MHD Waves observed at equatorial latitudes with magnitude of Interplanetary Magnetic Field. International Journal of Advanced Science and Technology. 2020;29(4):2302-2309. Available from: http://sersc.org/journals/index.php/IJAST/issue/view/ 269.

12) Murphy KR, Inglis AR, Sibeck DG, Watt CEJ, Rae IJ. Inner Magnetospheric ULF Waves: The Occurrence and Distribution of Broadband and Discrete Wave Activity. Journal of Geophysical Research: Space Physics. 2020;125(9). Available from: https://dx.doi.org/10.1029/2020ja027887. 
13) Yumoto K. Long-period magnetic pulsations generated in the magnetospheric boundary layers. Planetary and Space Science. 1984;32(10):1205-1218. Available from: https://dx.doi.org/10.1016/0032-0633(84)90064-3.

14) Wu CC. Kelvin-Helmholtz instability at the magnetopause boundary. Journal of Geophysical Research. 1986;91(A3). Available from: https://dx.doi.org/ 10.1029/ja091ia03p03042.

15) Southwood DJ. The hydromagnetic stability of the magnetospheric boundary. Planetary and Space Science. 1968;16(5):587-605. Available from: https://dx.doi.org/10.1016/0032-0633(68)90100-1.

16) Greenstadt EW. Statistics of bow shock nonuniformity. Journal of Geophysical Research. 1973;78(13):2331-2336. Available from: https://dx.doi.org/10. 1029/ja078i013p02331.

17) Greenstadt EW, Mellott MM, McPherron RL, Russell CT, Singer HJ, Knecht DJ. Transfer of pulsation-related wave activity across the magnetopause: Observations of corresponding spectra by ISEE-1 and ISEE-2. Geophysical Research Letters. 1983;10(8):659-662. Available from: https://dx.doi.org/10. 1029/gl010i008p00659.

18) Tomomura K, Sakurai T, Kato Y. Satellite observations of magnetic fluctuations in the magnetosheath and the magnetosphere. In: and others, editor. Proc of the Faculty of Engineering. Tokai University (Japan). 1983;p. 1-1.

19) Ansari IA, Fraser BJ. A multistation study of low latitude Pc3 geomagnetic pulsations. Planetary and Space Science. 1986;34(6):519-536. Available from: https://dx.doi.org/10.1016/0032-0633(86)90090-5.

20) Burton RK, Russel CT, Chappel CR. The Alfven velocity in the magnetosphere and its relationship to ELF emissions. J Geophys Res (USA). 1970;75

21) Heilig B, Lühr H, Rother M. Comprehensive study of ULF upstream waves observed in the topside ionosphere by CHAMP and on the ground. Annales Geophysicae. 2007;25(3):737-754. Available from: https://dx.doi.org/10.5194/angeo-25-737-2007.

22) Ansari IA, Khan MT. Pc4 occurrence and itd dependence on Kp values at low latitudes in India. Indian J of Radio \& Space Phys. 1985;41:42-49. Available from: http://nopr.niscair.res.in/handle/123456789/13630.

23) Takahashi K, Liou K, Yumoto K, Kitamura K, Nosé M, Honary F. Source of Pc4 pulsations observed on the nightside. Journal of Geophysical Research. 2005;110(A12). Available from: https://dx.doi.org/10.1029/2005ja011093.

24) Vellante M. Ground/satellite signatures of field line resonance: A test of theoretical predictions. Journal of Geophysical Research. 2004;109(A6). Available from: https://dx.doi.org/10.1029/2004ja010392. 